\title{
Proposal and Evaluation of a Telerehabilitation Platform Designed for Patients With Partial Rotator Cuff Tears: A Preliminary Study
}

\author{
Salvador Israel Macías-Hernández, MD, MSc ${ }^{1}$, Diana Sureima Vásquez-Sotelo, MD $^{1}$, \\ Marco Vinicio Ferruzca-Navarro, $\mathrm{PhD}^{2}$, Susana Hazel Badillo Sánchez, $\mathrm{PhD}^{2}$, \\ Josefina Gutiérrez-Martínez, $\mathrm{PhD}^{3}$, Marco Antonio Núñez-Gaona, $\mathrm{MSc}^{3}$, Heriberto Aguirre-Meneses, $\mathrm{MSc}^{3}$, \\ Oscar Benjamín Velez-Gutiérrez, BSc ${ }^{4}$, Irene Tapia-Ferrusco, BSc $^{4}$, \\ María de los Ángeles Soria-Bastida, $\mathrm{MD}^{1}$, Roberto Coronado-Zarco, $\mathrm{MD}^{1}$, Juan Daniel Morones-Alba, MSc ${ }^{1}$
}

${ }^{1}$ Orthopedic Rehabilitation Division, Instituto Nacional de Rehabilitación, Mexico City;

${ }^{2}$ Department of Industrial Design, UAM-Azcapotzalco, Mexico City;

${ }^{3}$ Subdirection of Technology/Biomedical Engineering, Instituto Nacional de Rehabilitación, Mexico City;

${ }^{4}$ Physical Therapy Division, Instituto Nacional de Rehabilitación, Mexico City, Mexoco

\begin{abstract}
Objective To propose and evaluate the effectiveness of a telerehabilitation platform designed for patients with rotator cuff (RC) tears.

Methods During the first study phase, a virtual service platform that included information on RC tear pathology, joint care, and a series of instructions regarding therapeutic exercise was designed and created. Subsequently, in the clinical phase, a quasi-experimental study was performed. The platform was tested on patients and evaluated at baseline and at 1,2,3, and 6 months with respect to their pain levels and functionality on the Constant-Murley (CM) scale.

Results Eleven patients were included, 5 women and 6 men, with a median age of 55 years (range, 42-68 years). Pain diminished from a baseline value of $64 \mathrm{~mm}$ (range, $40-80 \mathrm{~mm}$ ) to $16 \mathrm{~mm}$ (range, $0-30 \mathrm{~mm}$ ) at 6 months $(\mathrm{p}<0.001)$. Points on the CM scale rose from a baseline value of 54 points (range, 51-66 points) to 85 points (range, $70-100$ points $)$ at 6 months $(\mathrm{p}=0.001)$. Functionality in daily living and work activities, movement, and strength exhibited significant changes at 6 months $(\mathrm{p}<0.05)$.
\end{abstract}

Received October 2, 2015; Accepted November 11, 2015

Corresponding author: Salvador Israel Macías-Hernández

Department of Osteoarticular Rehabilitation, Orthopedic Rehabilitation Division, Instituto Nacional de Rehabilitación, Av. México-Xochimilco 289, Col. Arenal de Guadalupe, Delegación Tlalpan, Mexico City 14389, Mexico. Tel: +52-55-59991000, Fax: +52-55-9991000, E-mail: drisraelmacias@gmail. com

ORCID: Salvador Israel Macías-Hernández (http://orcid.org/0000-0003-1469-6128); Diana Sureima Vásquez-Sotelo (http://orcid.org/0000-00015479-9290); Marco Vinicio Ferruzca-Navarro (http://orcid.org/0000-0003-2415-586X); Susana Hazel Badillo Sánchez (http://orcid.org/0000-00023658-244X); Josefina Gutiérrez-Martínez (http://orcid.org/0000-0002-2022-5835); Marco Antonio Núñez-Gaona (http://orcid.org/0000-0002-84506003); Heriberto Aguirre-Meneses (http://orcid.org/0000-0002-2655-1367); Oscar Benjamín Velez-Gutiérrez (http://orcid.org/0000-0002-1700-9488); Irene Tapia-Ferrusco (http://orcid.org/0000-0001-9891-2005); María de los Ángeles Soria-Bastida (http://orcid.org/0000-0002-7842-4247); Roberto Coronado-Zarco (http://orcid.org/0000-0002-8268-9686); Juan Daniel Morones-Alba (http://orcid.org/0000-0002-3961-5243).

(c) This is an open-access article distributed under the terms of the Creative Commons Attribution Non-Commercial License (http://creativecommons.org/ licenses/by-nc/4.0) which permits unrestricted noncommercial use, distribution, and reproduction in any medium, provided the original work is properly cited. Copyright (C) 2016 by Korean Academy of Rehabilitation Medicine 
Conclusion Significant changes were observed in pain and functionality in this group of participants who used a telerehabilitation platform. To the best of our knowledge, this is the first study that included a specific program for RC tears.

Keywords Telemedicine, Rehabilitation, Rotator cuff, Shoulder, Remote consultation

\section{INTRODUCTION}

Telerehabilitation (TR) consists of providing rehabilitation services at a distance with the help of technology [1]. It is an alternative to conventional therapeutic methods, because it may enhance compliance to the programs in patients who have difficulty in attending the rehabilitation centers [2]. It ensures an interaction between the patient and one or more healthcare workers through a method to transmit data. In theory, it allows supervision during exercise sessions, adherence and adequate performance, and clinical evolution [2-5].

The shoulder is a complicated structure, with unique anatomical and biomechanical characteristics that are particularly difficult to treat and rehabilitate. Correct functioning is essential for a person to perform basic daily living activities, indicating that an injury can cause disability [6]. Among shoulder pathologies in adults, rotator cuff (RC) injuries show the highest incidence [7].

Conservative treatment of RC tears includes rehabilitation interventions to diminish pain and inflammation, favor tendon healing, and improve movement, functioning, and muscle strengthening [8,9]. They can also include patient educational strategies in order to avoid progression or recurrence of the injury [10-12]. Conventional rehabilitation programs have proven effective in a high proportion of patients with RC tears $[13,14]$.

Evidence has shown that TR has comparable or even better results than conventional rehabilitation; for example, in patients undergoing knee arthroplasty $[15,16]$, patients with sequels of stroke [17] or patients with heart failure [18] among others. Almost all interventions include direct remote interaction via Internet video chat, but few studies have included systems that are specifically designed for conditions or unique locations [16].

Evidence-based practice makes it necessary to prove the usefulness of new systems that are designed specifically for unique purposes through clinical trials, thereby revealing any advantage. This also opens any windows of opportunity for their implementation in other pathologies and settings, and for considering the generalization.

The objective of this study was to propose and evaluate the therapeutic effectiveness of a TR platform designed to reduce shoulder pain and to increase functionality in patients with partial RC tears.

\section{MATERIALS AND METHODS}

A TR platform was designed by using a user centric design method [19].

During the first phase, the design team created a conceptual model based on the needs proposed by healthcare professionals (physicians and therapists). Subsequently, multimedia content (video, illustrations, and text descriptions) was designed and tailored to the platform, including functional elements of navigability. Analysis, design, and implementation of the platform were performed at the Instituto Nacional de Rehabilitación (INR) in Mexico City in collaboration with the Universidad Autónoma Metropolitana (UAM) of Mexico.

A graphical user interface was created in Spanish to connect the INR and users (physicians, patients, caregivers and therapists), and it was part of a preliminary technology development that encompassed various components of the TR platform; the patients interact with physicians and therapists with the use of sample videos. This way they could learn about the proper execution of their therapeutic exercises and then record a video while they perform their therapy and receive a feedback from healthcare professionals or clear any doubts on their performance or symptoms perceived by them (Fig. 1).

This system was designed to provide an interactive environment so that the patients could access rehabilitation resources: education on the pathology, injury care, joint hygiene, activity modification, and therapeutic exercises. To the best of our knowledge, this model has not been described previously.

The platform was composed of two basic modules. One 


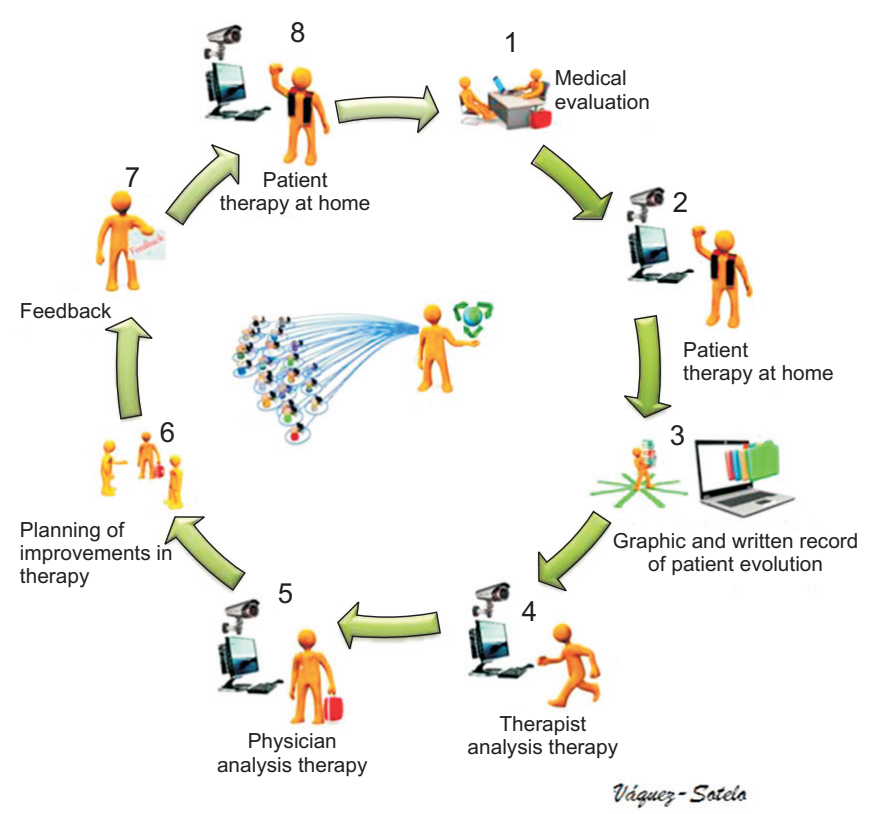

Fig. 1. Conceptualization of the telerehabilitation model for patients of the National Institution of Rehabilitation.

module was denominated "Get Active" and consisted of 21 videos, each video having a duration of 1 to 2 minutes, which contained verbal and written instructions on the use of thermotherapy and exercise. The other module, called "Learn", provided the patients with information on different care activities and how to modify their daily activities according to their condition (Figs. 2, 3).

Once the platform was completed, usability tests were performed before providing access to the participants. Upon completion of system design and creation, a clinical feasibility trial was conducted to prove its usability; which was evaluated in healthy volunteer subjects, using an eye tracking system, and later with a survey on the access, use, feedback, and recommendation for use. Once it was feasible to use the system, we proceeded to begin the proposal stage, with a functional prototype based on the results of the first phase.

\section{Clinical phase}

A prospective, quasi-experimental study was performed. Patients were recruited from the INR Orthopedic Rehabilitation Outpatient Clinic and were eligible for inclusion if they were $>18$ years of age, had a diagnosis of partial RC tears (clinical and by ultrasound), had symptoms for less than 6 months evolution time, had not received rehabilitation treatment previously and were not

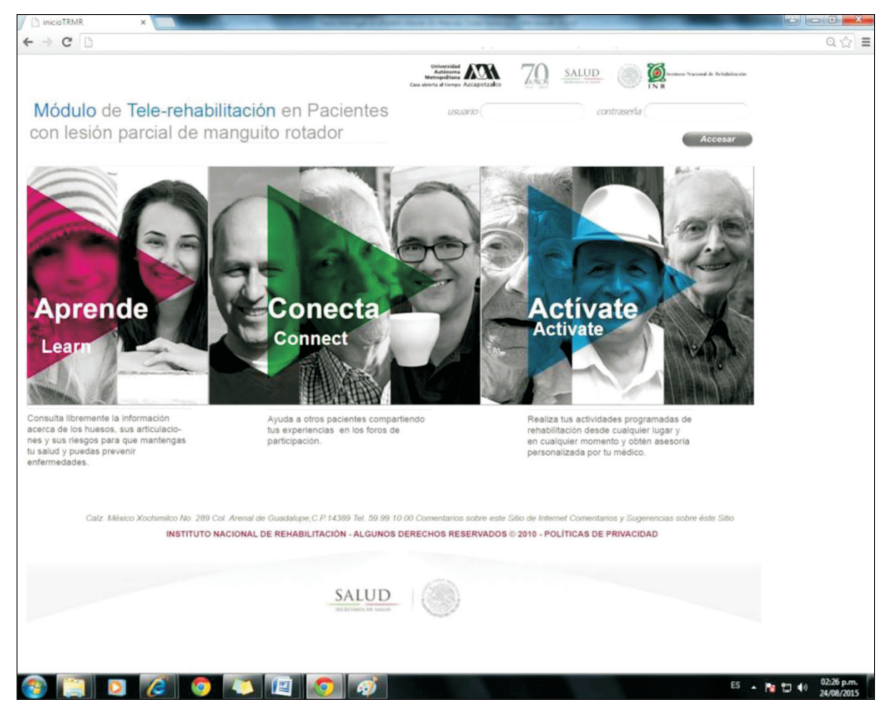

Fig. 2. Components and access to the platform modules (as designed for patients; in Spanish).

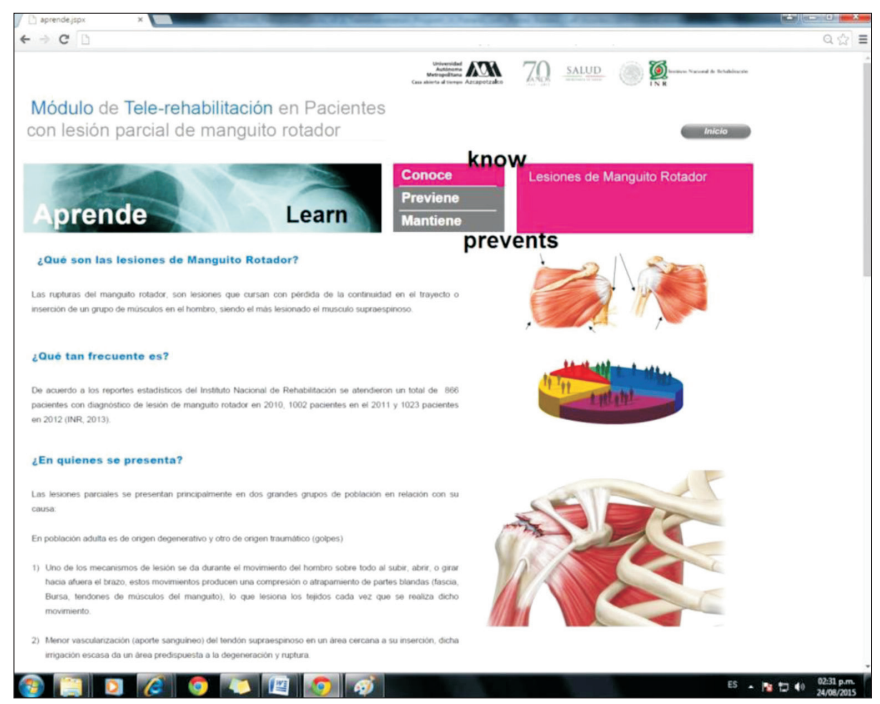

Fig. 3. Information on the pathology, care, joint hygiene, and general information (as designed for patients; in Spanish).

candidates for initial surgical treatment. An important criterion was that patients should be residing outside the Mexico City or should have encountered difficulty in accessing the INR installation due to personal reasons or distance. No limits were placed on the gender of the patient.

Subjects confirmed that they possessed a computer with Windows 7 or a more recent operating system, as well as a camera and internet connection, and that either 
a caregiver and/or the patient knew how to operate the equipment. Patients with complete tears or full thickness tears, calcific tendonitis, or a history of previous surgical events were excluded from the study.

A clinical evaluation was performed that included the following: a clinical interview, physical exploration, and administration of the Constant-Murley (CM) scale. Patients were invited to participate in the study, and they signed the informed consent form and gave permission to use and publish their images and videos for the purpose of the project. Later the same day, a shoulder ultrasound was performed to confirm and evaluate the degree, type, and location of the injury.

For the assessment of muscle strength, a dynamometer of the Braunker brand was used, and patients performed concentric isotonic contraction of the injured shoulder during flexion and abduction in the scapular plane; the results were reported in pounds.

Based on this evaluation, a physician specialized in Physical Medicine and Rehabilitation assigned the TR program, choosing the platform's most appropriate videos or instructions for each patient. It included the following: thermotherapy; movement; stretching, and strengthening. Patients, along with a companion, were personally instructed on the use of the platform for 1 hour. During this session, their questions were answered regarding how to access and use the system, perform their prescribed therapies, interact with therapists, receive feedback, and upload their videos onto the platform.

A user name and password were provided to the patient so that they could access the virtual site. Patients were expected to devote approximately 30 minutes per day, 5 days a week, to the program.

Each time the patients connected to the program, they had the possibility of gaining general information on their condition, becoming more familiar with care activities or modifications in their environment, checking the method for performing physical therapy through individually assigned videos, and receiving feedback from health professionals in order to improve the manner in which they perform their therapy. All accesses, length of time spent, and logout time were recorded in the system.

As part of the program and feedback, twice a week, the patients were asked to record how they were performing their therapy and to send the video to the platform. This

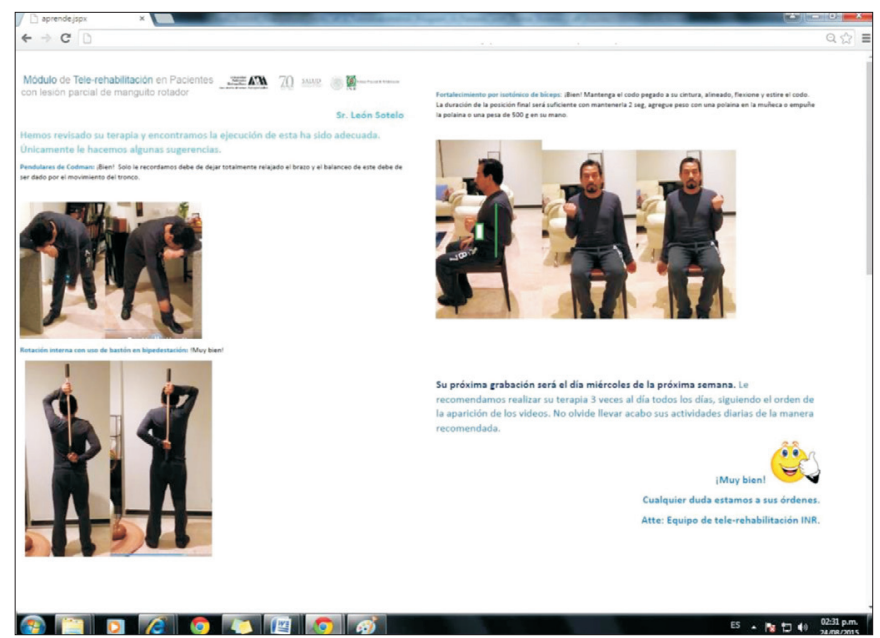

Fig. 4. Personalized feedback to patients and corrections on exercise techniques (system in Spanish).

material was evaluated by physicians and therapists, and according to the patient's performance, written feedback was sent to each patient with the same frequency within the system (Fig. 4).

Functional evaluations were performed at baseline and at $1,2,3$, and 6 months. At each evaluation, the physician modified the prescribed therapy in the system so that the patients could progress further based on their individual symptomatology, including types of exercises, techniques, and number of sets or repetitions. At the end of the 3-month evaluation, the patients continued with their individual therapy programs with monthly feedback on the platform until month 6 .

Outcomes comprised pain measured by the visual analog scale (VAS) and functionality on the CM scale (which includes the qualitative measurement of pain and quantitative movement and strength through the use of a dynamometer).

Sample size was not calculated as this was a preliminary study due to the technical difficulties that could arise during the initial use of the system.

\section{Statistical analysis}

Descriptive statistics were employed to summarize the data, using medians and ranges as central tendency and dispersion measurements. In order to confirm the hypothesis, non-parametric tests were utilized, assuming a non-normal distribution. Wilcoxon range tests were used for (quantitative) variables of functional outcome, 
comparing two related samples, or the Friedman test was employed to compare various related samples at different time periods. Fisher exact test was utilized to compare and measure nominal variables.

The protocol was registered with the INR Research Committee and it followed the institute's ethical guidelines, Good Clinical Practice (GCP), the Helsinki Declaration, and the Health Research Regulations appearing in the Mexican General Law of Health.

\section{RESULTS}

\section{Usability}

The eye tracking system allowed for measuring the time and location of the images and buttons, and deciding the most appropriate location on the screen, for the buttons, text and images for the system. Seven volunteers rated the use of the system. With respect to access to the platform, $4(57.1 \%)$ subjects rated it as excellent and $3(42.9 \%)$ subjects rated it as very good. With respect to the use of the platform, 6 (85.7\%) subjects rated it as excellent and 1 $(14.3 \%)$ subject rated it as very good. All subjects received a post-use platform feedback and $7(100 \%)$ subjects rated it as excellent and recommended its use by others.

\section{Clinical phase}

A total of 20 patients were recruited, of which 5 patients were excluded for having complete or massive tears, 2 patients were excluded for having calcific tendonitis, and 2 patients were excluded for being candidates for initial surgery. For the final analysis, a total of 11 patients were included, 5 women and 6 men, whose median age was 55 years (range, 42-68 years). The median symptom evolution time was 3.5 months.

Table 1. Pain outcome measured by the visual analog scale

\begin{tabular}{lcc}
\hline & Median (range) & p-value $^{\text {a) }}$ \\
\hline Baseline & $64(40-80)$ & - \\
1 month & $31(0-40)$ & 0.017 \\
2 months & $22(0-40)$ & 0.046 \\
3 months & $20(0-50)$ & 0.317 \\
6 months & $16(0-30)$ & 0.17
\end{tabular}

${ }^{\text {a) }}$ Results of the Wilcoxon test performed on pairs of time analysis. Friedman test for the total difference within 6 months showed a $\mathrm{p}<0.001$.
None of the patients engaged in work or leisure activities that were described as risk factors for shoulder injuries.

With respect to the injury type, 7 patients had a sole supraspinatus injury, 2 patients had a supraspinatus and infraspinatus injury, and 2 patients had a supraspinatus and subscapularis injury. Six patients presented with injuries to their dominant arm, and 5 patients presented with injuries to their non-dominant arm.

All patients completed their initial evaluation, as well as follow-up visits; none of the patients were lost to followup.

Pain outcomes on the VAS are depicted in Table 1. Qualitative pain measurement according to the CM scale at baseline revealed that $85 \%$ of the patients had

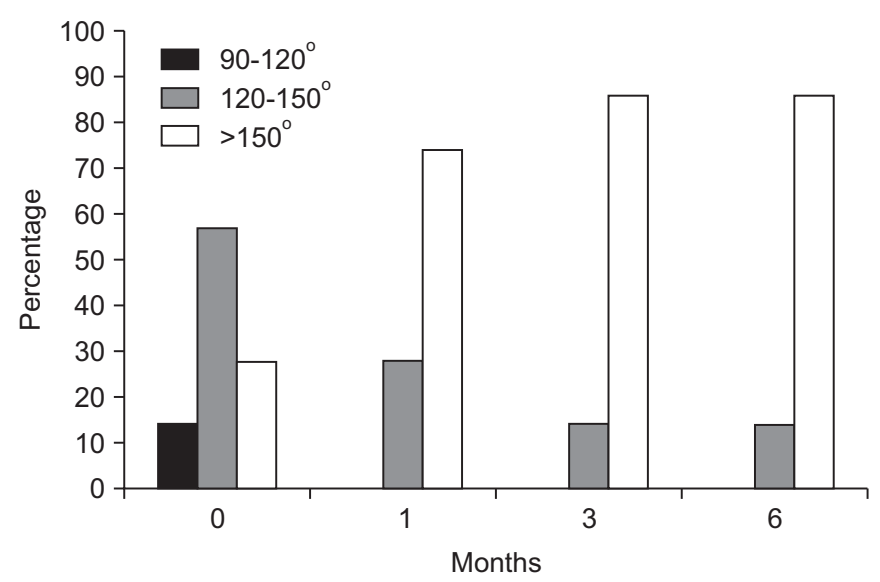

Fig. 5. Measurement of mobility in flexion and its progression over time according to the Constant-Murley scale $(\mathrm{p}<0.05)$.

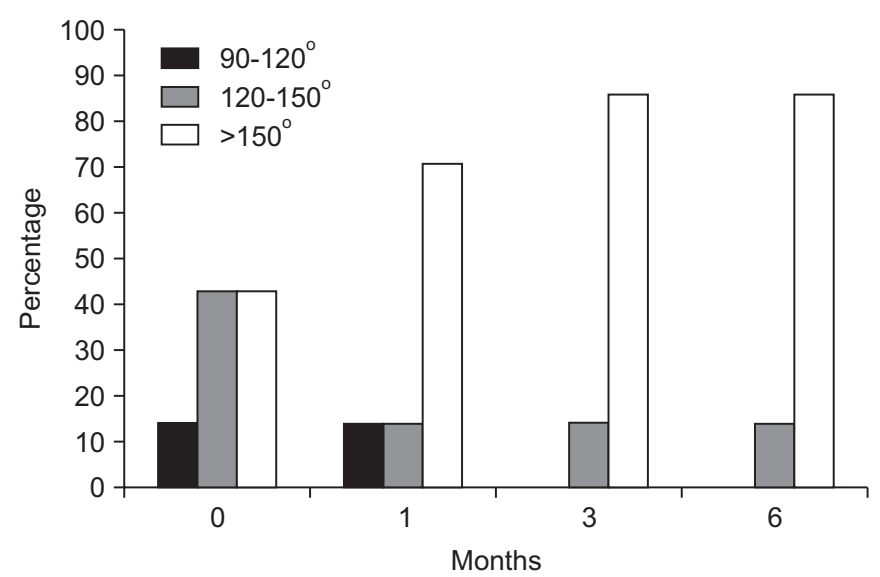

Fig. 6. Measurement of mobility in abduction and its progression over time $(\mathrm{p}<0.05)$. 
Table 2. Muscle strength outcome (unit, pounds)

\begin{tabular}{lc}
\hline & Median (range) \\
\hline Baseline & $12(5-18)$ \\
\hline 1 month & $13(7-24)$ \\
2 months & $13(7-23)$ \\
3 months & $15(8-24)$ \\
6 months & $18(8-27)$ \\
\hline p-value & 0.001 \\
\hline
\end{tabular}

moderate pain and $15 \%$ of the patients had severe pain; at 1 month, $44 \%$ of the patients had no pain, $22 \%$ of the patients had moderate pain, and $22 \%$ of the patients had minimal pain, and at 3 and 6 months, $46 \%$ of the patients remained free of pain and $54 \%$ of the patients had minimal pain $(\mathrm{p}<0.01)$.

The evaluation of daily living and work activities according to the CM scale demonstrated that $100 \%$ of the patients had moderate limitation, but in evaluations at 1,3 , and 6 months, $68 \%$ of the patients remained without limitations $(\mathrm{p}<0.01)$.

Evaluation of movement of the flexors and abductors on the scale is presented in Figs. 5 and 6. With respect to muscle strength, progression over time is presented in Table 2. Total classification with the baseline CM scale and follow-ups is illustrated in Table 3.

All patients reported adequate acceptability of the platform and they would recommend the said platform to others in the future.

\section{DISCUSSION}

In this study, following the use of the TR platform, patients showed a significant decrease in pain, and improved movement, functioning, and muscular strength.

These latter differences appeared from months 1 and 2 of the treatment, at which point the change in all parameters was highly significant. During follow-ups at months 3 and 6 , significant modifications were not observed, but improvements were maintained; hence, changes evaluated between months 1 and 6 showed a significant difference in pain and functioning.

With respect to other TR programs for the shoulder, Van Straaten et al. [20] reported that a high dose of home exercise program of rotator cuff and scapular stabilization exercises significantly reduced shoulder pain in patients
Table 3. Total scores of Constant-Murley scale measurements

\begin{tabular}{lcc}
\hline & Median (range) & p-value $^{\text {a) }}$ \\
\hline Baseline & $54(51-66)$ & - \\
1 month & $74(64-97)$ & 0.018 \\
2 months & $81(66-98)$ & 0.048 \\
3 months & $82(68-98)$ & 0.253 \\
6 months & $85(70-100)$ & 0.365 \\
\hline
\end{tabular}

${ }^{a)}$ Comparison of the differences between pairs of time. Comparison of the differences between all evaluated times $(\mathrm{p}=0.001)$.

with spinal cord injuries who were wheelchair users, and it was supervised at distance. Eriksson et al. [21] described their experience in 10 patients who received rehabilitation via video conference for 2 months after undergoing shoulder arthroplasty, and they reported that it was a useful and successful intervention.

Unlike the previous programs, the one proposed by us, is not simply video conferencing or chat, but it includes a system of comprehensive, dedicated communication and feedback to patients with RC tears that allows an interaction which is not dependent on the specific time or remains connected simultaneously.

In addition to improvement in the medical condition, elimination of transportation time and treatment costs promoted therapeutic adherence and adequate execution and lowering of the burden of treatment. This platform offers advantages to patients who have difficulty in accessing rehabilitation services, not only because of the distance, but also due to the difficulty caused by the same disability for which they are being treated, and the specific schedules required in other types of remote rehabilitation.

It is important to include a larger number of patients and a control group receiving conventional treatment in order to corroborate whether TR is equivalent to or even superior than conventional therapy.

Although this is an auto-controlled study, which is considered to be a weak design, there is evidence that the natural history of symptomatic rotator cuff injuries indicates that they mostly tend to progression and not to spontaneous resolution [22-24]; hence, the outcome of implementation of the TR program is unlikely to be due to a placebo effect or the natural history of disease. It is noteworthy that the CM scale includes quantita- 
tive assessments of mobility and strength, and the study showed significant improvement in these areas.

In the future, it is possible that other authors may develop TR platforms that include patient education, an exercise program focused on the patient and pathology, and a feedback system and monitoring of patients, which can provide many advantages for remote rehabilitation programs, and could be used for highly prevalent pathologies such as osteoarthritis or osteoporosis, and not simply offer videoconferencing services.

\section{CONFLICT OF INTEREST}

No potential conflict of interest relevant to this article was reported.

\section{REFERENCES}

1. Brennan DM, Barker LM. Human factors in the development and implementation of telerehabilitation systems. J Telemed Telecare 2008;14:55-8.

2. Hailey D, Roine R, Ohinmaa A, Dennett L. Evidence of benefit from telerehabilitation in routine care: a systematic review. J Telemed Telecare 2011;17:281-7.

3. Rizzo AA, Strickland D, Bouchard S. The challenge of using virtual reality in telerehabilitation. Telemed J E Health 2004;10:184-95.

4. Hill AJ, Theodoros D, Russell T, Ward E. Using telerehabilitation to assess apraxia of speech in adults. Int $\mathrm{J}$ Lang Commun Disord 2009;44:731-47.

5. Ward EC, Sharma S, Burns C, Theodoros D, Russell T. Managing patient factors in the assessment of swallowing via telerehabilitation. Int J Telemed Appl 2012;2012:132719.

6. Barr KP. Rotator cuff disease. Phys Med Rehabil Clin N Am 2004;15:475-91.

7. Littlewood C, May S, Walters S. Epidemiology of rotator cuff tendinopathy: a systematic review. Shoulder Elbow 2013;5:256-65.

8. Macias-Hernandez SI, Perez-Ramirez LE. Eccentric strength training for the rotator cuff tendinopathies with subacromial impingement: current evidence. Cir Cir 2015;83:74-80.

9. Moosmayer S, Lund G, Seljom US, Haldorsen B, Svege IC, Hennig T, et al. Tendon repair compared with physiotherapy in the treatment of rotator cuff tears: a randomized controlled study in 103 cases with a fiveyear follow-up. J Bone Joint Surg Am 2014;96:1504-14.

10. Ellman H. Diagnosis and treatment of incomplete rotator cuff tears. Clin Orthop Relat Res 1990;(254):6474.

11. Lewis JS. Rotator cuff tendinopathy. Br J Sports Med 2009;43:236-41.

12. Clement ND, Nie YX, McBirnie JM. Management of degenerative rotator cuff tears: a review and treatment strategy. Sports Med Arthrosc Rehabil Ther Technol 2012;4:48.

13. Gomoll AH, Katz JN, Warner JJ, Millett PJ. Rotator cuff disorders: recognition and management among patients with shoulder pain. Arthritis Rheum 2004;50:3751-61.

14. Krischak G, Gebhard F, Reichel H, Friemert B, Schneider F, Fisser C, et al. A prospective randomized controlled trial comparing occupational therapy with home-based exercises in conservative treatment of rotator cuff tears. J Shoulder Elbow Surg 2013;22:11739.

15. Tousignant M, Moffet H, Boissy P, Corriveau H, Cabana F, Marquis F. A randomized controlled trial of home telerehabilitation for post-knee arthroplasty. J Telemed Telecare 2011;17:195-8.

16. Piqueras M, Marco E, Coll M, Escalada F, Ballester A, Cinca $\mathrm{C}$, et al. Effectiveness of an interactive virtual telerehabilitation system in patients after total knee arthroplasty: a randomized controlled trial. J Rehabil Med 2013;45:392-6.

17. Kowalczewski J, Chong SL, Galea M, Prochazka A. Inhome tele-rehabilitation improves tetraplegic hand function. Neurorehabil Neural Repair 2011;25:412-22.

18. Piotrowicz E, Stepnowska M, Leszczynska-Iwanicka K, Piotrowska D, Kowalska M, Tylka J, et al. Quality of life in heart failure patients undergoing home-based telerehabilitation versus outpatient rehabilitation: a randomized controlled study. Eur J Cardiovasc Nurs 2015;14:256-63.

19. Deaton M. The elements of user experience: usercentered design for the web. Interactions 2003;10:4951.

20. Van Straaten MG, Cloud BA, Morrow MM, Ludewig $\mathrm{PM}$, Zhao KD. Effectiveness of home exercise on pain, function, and strength of manual wheelchair users with spinal cord injury: a high-dose shoulder pro- 
gram with telerehabilitation. Arch Phys Med Rehabil 2014;95:1810-7.e2.

21. Eriksson L, Lindstrom B, Ekenberg L. Patients' experiences of telerehabilitation at home after shoulder joint replacement. J Telemed Telecare 2011;17:25-30.

22. Safran O, Schroeder J, Bloom R, Weil Y, Milgrom C. Natural history of nonoperatively treated symptomatic rotator cuff tears in patients 60 years old or younger.
Am J Sports Med 2011;39:710-4.

23. Yamanaka K, Matsumoto T. The joint side tear of the rotator cuff: a followup study by arthrography. Clin Orthop Relat Res 1994;(304):68-73.

24. Eljabu W, Klinger HM, von Knoch M. The natural history of rotator cuff tears: a systematic review. Arch Orthop Trauma Surg 2015;135:1055-61. 